\title{
Morphological Characteristics of Batuah Red-Fleshed Durian (Durio graveolens), an Endemic Exotic Plant from East Kalimantan, Indonesia
}

\author{
Odit Ferry Kurniadinata*1, Song Wenpei², Rusdiansyah ${ }^{1}$ \\ ${ }^{1}$ Faculty of Agriculture, Universitas Mulawarman, Samarinda, East Kalimantan Province, Indonesia \\ ${ }^{2}$ College of Horticulture and Landscape Architecture, Zhongkai University of Agriculture and Engineering, Guangzhou, China \\ *Corresponding author: odit.ferry@faperta.unmul.ac.id
}

\section{ARTICLE HISTORY \\ Received : 4 February 2020 \\ Revised : 28 March 2020 \\ Accepted : 17 April 2020}

\section{KEYWORDS}

Tropical Rain Forest

Local Fruit

Cross Breeding

Germplasm

Preservation

Red Aril

\begin{abstract}
Kalimantan Island is rich in genetic resources and species diversity of Durio spp. plant. The large number of Durio species that grow in Kalimantan illustrates that this area is the most important distribution center for durian relatives. The best-known edible durians are Durian (Durio zibethinus). However, Kalimantan also has various types of Durian that are not yet widely known and have superior potential. One of the unique and exotic plants is the red flesh Durian in East Kalimantan, Indonesia. The fruit of this plant is unique because it has red flesh. At present, there is no morphological identification of this East Kalimantan Durio graveolens plant. The study aimed to identify the morphological character of Batuah D. graveolens from East Kalimantan, Indonesia. This research was carried out by collecting data and information about the morphological characteristics of the plant and fruits. The results of the study successfully identified Batuah D. graveolens from East Kalimantan as a plant diverts from another Durio spp. plant known like D. zibethinus and D. kutejensis especially for red flesh character.
\end{abstract}

This is an open access article under the CC-BY-SA license.

\section{INTRODUCTION}

Kalimantan is the largest island in Indonesia, with high level of biodiversity in the world. Kalimantan, especially East Kalimantan, is a place of mega biodiversity with humid tropical forest climate conditions (Debnath, et al., 2014; Ercisli \& Sagbas, 2017). The humid tropical climate is a climate with humidity above $90 \%$, high rainfall (more than $1500 \mathrm{~mm} /$ year), annual temperature above $18^{\circ} \mathrm{C}$, and the difference between the rainy season and the dry season is not very clear (Poepenoe, 1974). One of the rich diversity that exists is the presence of various types of tropical fruits, most of which are endemic to East Kalimantan. Indonesia is one of the eight centers of plant genetic diversity in the world, especially for tropical fruits such as durian (Biodiversity International, 2007; Brown, 1997). At present, it is recorded that of around 27 species of Durio worldwide, 18 of them are grown in Kalimantan, 11 are in Malaya, and seven are in Sumatra (Milow, et al., 2014). The great diversity of species and sources of germplasm Durio spp. in Indonesia is very important as basic capital for breeders (Poerwanto, 2003; Ryugo, 1988; Chakravarty, et al., 2016).
The high number of Durio species that grow in Kalimantan illustrates that this area is the most important distribution centre for durian relatives. In addition to being rich in durian diversity, Indonesia is also rich in the diversity of sources of germplasm from Durio spp. In Indonesia, there are quite a lot of durian cultivars that differ from one another in taste, aroma, and color of the flesh. Even durian seeds can be found without seeds. From plant breeding, it is expected that superior seeds will be obtained both in quality and fruit production. This rich diversity of species and germplasm has not been utilized optimally. Therefore, plant breeding in durian relatives (Durio spp.) in Indonesia needs to produce superior cultivars/seeds (The Indonesian Ministry of Agriculture, 2011). This can be done by collecting data and information about the rich diversity of species and sources of germplasm Durio spp. in Indonesia (Belgis, et al., 2015). The next step is select the types of sources of germplasm that have more value. With the availability of diversity in germplasm types or sources, the desired superior cultivars/seeds will be assembled. To be able to determine the type of plants to be planted, it must be known the characteristics of these plant types, especially 
in relation to climate, soil, and growth velocity factors (Marschner, 1995; Bernier, et al., 2018; Sundari, 2015). Plants with the cross-pollination mechanism as well as the genus Durio spp. derived from natural crosses in nature is very difficult to obtain with potentially superior character (Chakravarty, et al., 2016). Therefore it is important to do a morphological identification activities and documentation of potential superior commodities in East Kalimantan.

Kutai Kertanegara Regency has many kinds of durian trees that have been traditionally and conventionally planted for a long time, and this has caused many interesting nature modifications of the Durio spp. plant character to be studied and do scientifically identified. Durio graveolens is one of durian species found in East Kalimantan. It has a unique size and good taste. This study aims to find, identify, and initially characterize of Batuah D. graveolens in Kutai Kertanegara district, East Kalimantan, Indonesia, as potentially superior endemic fruit plants

\section{MATERIALS AND METHODS}

Observations were carried out on productive crops, having produced more than three times, and productive. Identification was done by used survey method and in-depth interview to the owner of plants and farmers, as well as related stakeholders to explore the potential of $D$. graveolens fruit crops, and then made the characterization of durian plants. The experiment was conducted in Kutai Kertanegara, East Kalimantan, Indonesia, Agronomy Laboratory, Faculty of Agriculture, Universitas Mulawarman, Samarinda, East Kalimantan Province, Indonesia, from January to September 2019. Research was conducted used International Plant Genetic Resources Institute (IPGRI) morphological characteristics.

\subsection{Statistical Data Analysis}

This research was conducted by using a descriptive method of exploration. Sampling methods with purposive sampling, by tracing the primary data and secondary data from the informer, either directly from the key person(s) and library data.

\section{RESULTS AND DISCUSSIONS}

\subsection{The Origin of $D$. graveolens}

Kalimantan Island is one of the centres of diversity of durian plants (Durio spp.). Generally, durian trees in Kalimantan are grow wildly in primary or mixed forests, and residents in gardens have planted only a small portion. Type D. zibethinus Murray (durian) can be found around Indonesia and another country nearby. This type of durian habitat is in primary and secondary forests and can grow on various types of soil. This type of durian is widely cultivated by people in Kalimantan, including in East Kalimantan (Uji, 2005), although it has not used optimal cultivation technology.

The potential to find new various types of durian in Kalimantan is very large. Kurniadinata et. al (2019) success identifying six new potential superior plants varieties from natural cross breading of durian and lai plants which are endemic plants in Kalimantan. D. graveolens is a relative of durian, which is also an endemic plant in Kalimantan. This species has different fruit morphological characters from durian plants, especially for the flesh colour. Its tree is almost the same as $D$. zibethinus, but the leaves are wider than other durians. Trunk surface is rough, growth straight, with irregular crown shape and branching density medium to dense. The colour of its skin fruit is an orange yellow to orange, and the spines are dense, short, and sharp. The flesh of is drier than the other types of durian, with red, dark colour and strong aroma. The existence of various genera of Durio spp. in the forests of Kalimantan makes it possible for plants with distinctive character, especially $D$. graveolens in East Kalimantan.

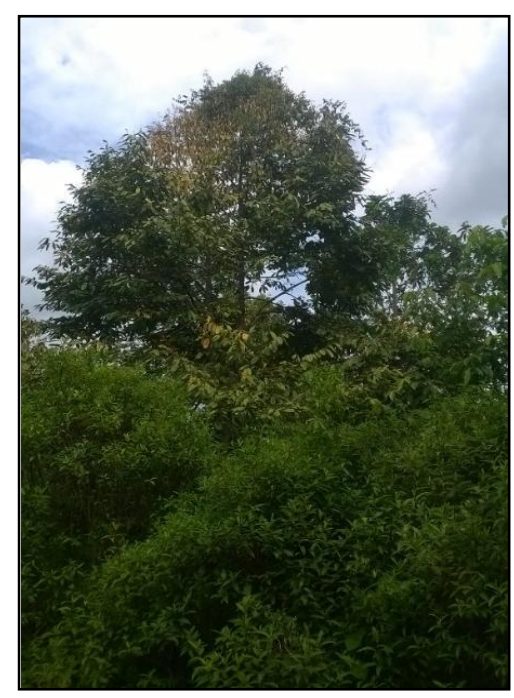

Figure 1. The appearance of D. graveolens tress surrounded by other trees 


\subsection{Morphological Characteristics of $D$. graveolens}

Observations were made in the production phase of $D$. graveolens plants that grow in Kutai Kertanegara, East Kalimantan. Based on observations of the morphological characteristics, there is diversity in the morphological characteristics of trees, leaves, flowers, fruits, and seeds. This species has an irregular crown shape with a tree height of approximately 10-15 meters (Figure 1). The stems are rough and grow straight, grey stems with a diameter of approximately $50 \mathrm{~cm}$.

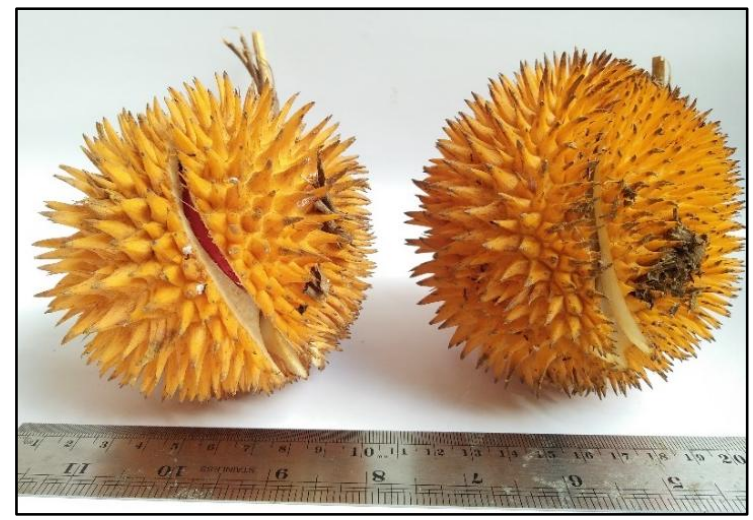

Figure 2. The appearance of D. graveolans fruit

The fruit colour is orange yellow to orange with bright intensity (Figure 2). Its fruit length is $10-13 \mathrm{~cm}$ with a diameter of $9-10 \mathrm{~cm}$. The fruit consists of 5 segments, with aryl thickness in a medium to thick scale. It has red flesh with a slight sweet taste and soft texture. $D$. graveolens from East Kalimantan also has dark red flesh colour, with flesh thickness are medium with soft texture (Figure 3). Flesh is non-juicy with fair creaminess and has a strong aroma/odour. The unique odour of this $D$. graveolens is different compared to $D$. zibenthinus odour.

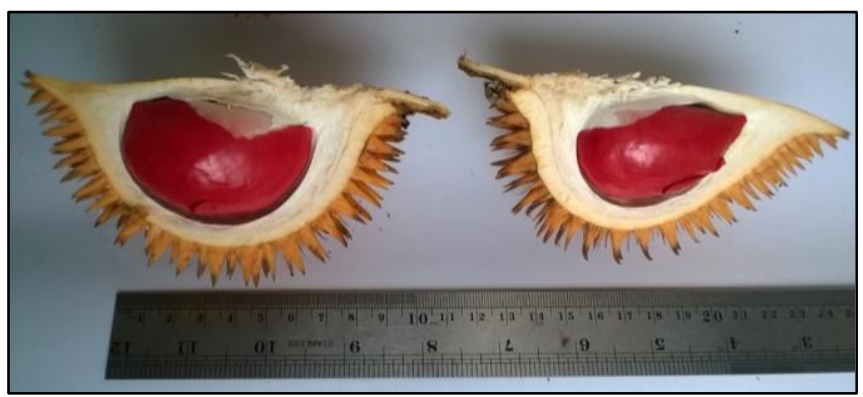

Figure 3. The segment and fleshes of D. graveolens

Each segment only has one flesh with seed and the seed length around 4.5-5 cm, with ellipsoid shape and dark brown colour. Some fruits only have 3 or 4 arils and seed each fruit because of some seed and aril, not growth in the rest of the segment (Figure 4).
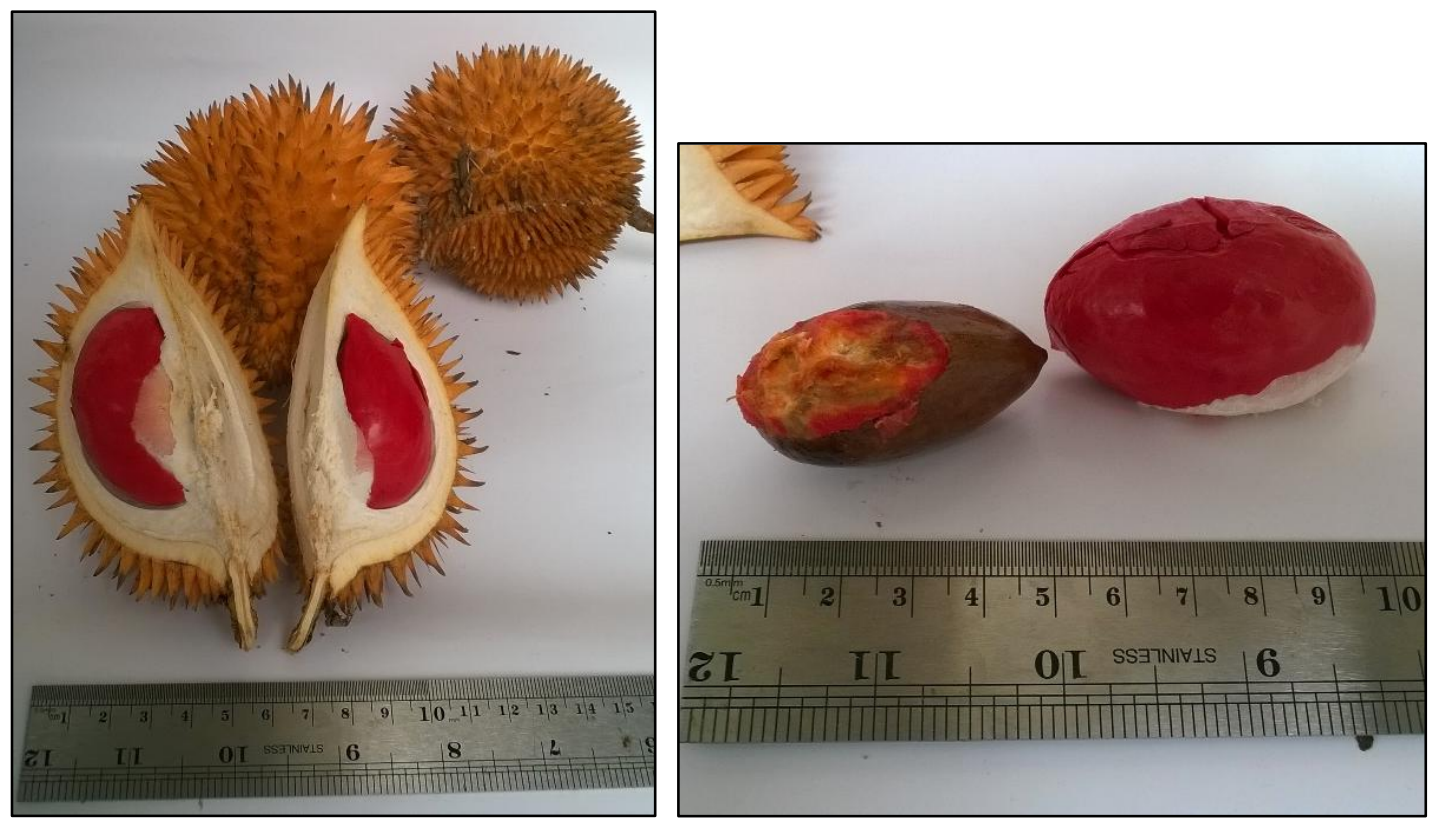

Figure 4. The appearance of fruits, segment, flesh, and the seed of D. graveolens 
Morphological characteristics of D. graveolens were presented in Table 1. Based on plant and fruit morphology characteristics, D. graveolens fruit from East Kalimantan has unique flesh color, different taste, and also different aroma if compared with D. zibethinus. The flesh color becomes the most unique character compare to other Durio spp plants, and it will become one of the advantages of this durian. Aside from being an exotic commodity, it is also a source of genetic diversity from Kalimantan, Indonesia, to develop another superior durian. Therefore, D. graveolens has a high potential economic value to be improved as superior commodities from East Kalimantan Province, Indonesia.

\section{CONCLUSION}

Batuah Durio graveolens fruit is a unique plant that differs from the other species of Durio spp. It has a red, dark color flesh, unique and strong aroma with soft texture aril. Therefore, Batuah Durio graveolens has a high potential economic value to be improved as Superior Commodities from East Kalimantan Province, Indonesia.

\section{ACKNOWLEDGEMENTS}

This project was supported by The Faculty of Agriculture Mulawarman University (Research Project 2019).

\section{REFERENCES}

Belgis, M., Wijaya, C.H., Apriyantono, A., Kusbiantoro, B. and Yuliana, N.D. (2015). Physicochemical differences and sensory profiling of six lai (Durio kutejensis) and four durian (Durio zibethinus) cultivars indigenous Indonesia. International Food Research Journal, 23(4), 1466-1473.

Bernier, G., Kinet, J.-M., \& Sachs, R. M. (2018). The Physiology of Flowering. doi:10.1201/9781351075688

Bioversity International. (2007). Descriptors For Durian (Durio zibethinus Murr.). Bioversity International. Rome.

Brown, M. J. (1997). Durio, a bibliographic review. Bioversity
International. Plant Genetic Resources Institute. India.

Chakravarty, S., Bhutia, K. D., Suresh, C. P., Shukla, G., \& Pala, N. A. (2016). A review on diversity, conservation and nutrition of wild edible fruits. Journal of Applied and Natural Science, 8(4), 2346-2353. doi:10.31018/jans.v8i4.1135

Debnath, S. C., Percival, D., \& Siow, Y. L. (2014). Biodiversity and conservation of wild small fruit species for a sustainable environment. In Conference: International Horticultural Congress, At Brisbane, Australia, Volume: Plant Genetic Resources For Climate Change.

Ercisli, S., \& Sagbas, H. I. (2017). Wild edible fruits: A rich source of biodiversity. ANADOLU Ege Tarımsal Araştırma Enstitüsü Dergisi, 27(2), 116-122.

Kurniadinata, O. F., Wenpei, S., Zaini, A., \& Rusdiansyah, R. (2019). Six Potential Superior Durian Plants Resulted by Cross Breeding of D. zibethinus and D. Kutejensis From East Kalimantan, Indonesia: Initial Identification. Journal of Tropical Horticulture, 2(2), 45-49. doi:10.33089/jthort.v2i2.24

Marschner H. 1995. Mineral Nutrition of Higher Plants. 2nd edition. Academic Press. London.

Milow, P., Malek, S. B., Edo, J., \& Ong, H.-C. (2013). Malaysian Species of Plants with Edible Fruits or Seeds and Their Valuation. International Journal of Fruit Science, 14(1), 1-27. doi:10.1080/15538362.2013.801698

Poepenoe, W. (1974). Manual of Tropical and Sub tropical Fruits. 2nd book. Hafner Press. New York.

Poerwanto, R. (2003). Teaching Materials for Fruit Cultivation. Module VII. Land Management and Fruit Garden Fertilization. Horticulture Study Program, Faculty of Agriculture. IPB. Bogor

Ryugo, K. (1988). Fruit culture: Its science and art. John Wiley and Sons Inc..

Sundari, S., Arumingtyas, E. L., Hakim, L., \& Azrianingsih, R. (2015). Morphological Variation of Local Durian (Durio zibethinus Murr.) on The Ternate Island. In Proceeding Conference International Biology and Life Science (ICOLIB)(UNEJ, Jember, 2015).

The Indonesian Ministry of Agriculture. 2011. The Guiding Book to make Description and test the Correctness of Horticulture Plant Varieties, The Decision of Agriculture Ministry, Republic of Indonesia. PP. 129. 
Appendix

Table 1. Characteristics of D. graveolens

\begin{tabular}{|c|c|}
\hline Trunk Surface & : Rought \\
\hline Trunk Growth habit & : Straight \\
\hline Crown Shape & : Irregular \\
\hline Tree Growth Habit & : intermediate \\
\hline Branching density & : medium to dense \\
\hline Bark Colour & : Grey \\
\hline leaf upper color & : Green \\
\hline leaf lower color & : Copperry Brown \\
\hline Leaf density & : medium \\
\hline Arrangement of leaves & : Alternate \\
\hline leaf attitude & : Drooping at 45 \\
\hline Petiole length (mm) & $: 20-25$ \\
\hline Petiole Width (mm) & $: 5-6$ \\
\hline leaf lenght $(\mathrm{cm})$ & $: 24-27$ \\
\hline leaf blade length & : long to very long \\
\hline leaf width $(\mathrm{cm})$ & $: 8-10$ \\
\hline leaf blade width & : wide to very wide \\
\hline Leaf blade shape & : Obovate-lanceolate \\
\hline Leaf apec shape & : Long Acuminate to Caudate \\
\hline Leaf base shape & : Round to Obtuse \\
\hline Leaf Blade Margin & : Entire \\
\hline Leaf Texture & : Papery \\
\hline Leaf Upper Surface Glossiness & : Glossy \\
\hline Leaf Lower Surface Glossiness & : Not Glossy \\
\hline Leaf Midrib Appearance & : Slightly Prominent \\
\hline Waxiness on Adaxial Leaf Surface & : Shiny \\
\hline Position of Infloresc & : Axillary \\
\hline Flowering Regularity & : Regular \\
\hline Flower Clustering Habit & : One flower per cluster \\
\hline Density of Flowers & : Sparse \\
\hline Flower Bud Shape & : Globose \\
\hline Flower Bud Apex Shape & : Rounded \\
\hline Apical Bud Color & : Greenish \\
\hline Calyx Shape & : Campanulate \\
\hline Calyx Tooth Apex Shape & : Pointed \\
\hline Number of Sepal & $: 5$ \\
\hline Sepal Color & : Light Yellow \\
\hline Flower Size & : large \\
\hline Pedicel length $(\mathrm{cm})$ & $: 3-5$ \\
\hline Number of Petals & $: 5$ \\
\hline
\end{tabular}




\begin{tabular}{|c|c|}
\hline Petal color & : Yellow \\
\hline Petal color intensity & : Light \\
\hline Petal margin color & : Green \\
\hline Petal shape & : Spathulate \\
\hline inner surface hairiness of petal & : Glabrous \\
\hline outer surface hairiness of petal & : Glabrous \\
\hline Type of Stamen & : Phalanx \\
\hline stamen exsertion relative to stigma & : Short \\
\hline Anther number & $: 43-50$ \\
\hline Anther shape & : Reniform \\
\hline Anther dehiscence & : Longitudinal \\
\hline Style length $(\mathrm{cm})$ & $: 5-6$ \\
\hline Style shape & : Straight \\
\hline hairiness on style & : Basal \\
\hline Stigma shape & : Capitate, 5-lobed \\
\hline Stigma color & : Yellow \\
\hline Stigma color intensity & : light \\
\hline Upper surface of stigma & : smooth \\
\hline Fruit ripening & : Non-synchronous \\
\hline Fruit dehiscene & : Yes \\
\hline Fruit bearing habit & : Biennial (alternate years) \\
\hline Fruit clustering habit & : One fruit per cluster \\
\hline Fruit Rind Thickness (cm) & $: 0.8-1.2$ \\
\hline Fruit Spine length & : short \\
\hline Fruits shape & : Globose \\
\hline Shape of fruit apex & : Pointed to Convex \\
\hline Shape of fruit base & : Convex \\
\hline Blossom end & : small \\
\hline Fruit stalk length & : short \\
\hline Fruit stalk attachment & : strong \\
\hline Fruit stalk color & : Brown \\
\hline Fruit spininess & : Spiny \\
\hline fruit spine shape & : Conical \\
\hline Surface of spine & : Glabrous \\
\hline Fruit spine density & : dense \\
\hline Fruit spine length & : short \\
\hline Fruit length [cm] & $: 10-13$ \\
\hline Fruit diameter $[\mathrm{cm}]$ & $: 9-10$ \\
\hline Fruit rind thickness & : Medium to thick \\
\hline Number of fruit segments/ locules & $: 5$ \\
\hline Fruit skin/rind color & : Orange Yellow to Orange \\
\hline Fruit skin/rind color intensity & : Light \\
\hline Shelf life [d] & $: 2-4$ \\
\hline
\end{tabular}




\begin{tabular}{ll}
\hline Aril thickness & $:$ medium \\
\hline Aril texture & $:$ soft \\
\hline Aril juiciness & $:$ Non-juicy \\
\hline Presence of fiber & $:$ Low \\
\hline Flesh creaminess & $:$ Fair \\
\hline Flesh taste & $:$ Slightly sweet \\
\hline Flesh aroma & $:$ Strong \\
\hline Flesh color & $:$ Red \\
\hline Flesh color intensity & $:$ Dark \\
\hline Number of rows of pulp units per locule & $:$ Single row \\
\hline Number of carpels per fruit & $: 5$ \\
\hline Persistence of calyx & $:$ Yes \\
\hline Persistence of stamen & $:$ Yes \\
\hline Easiness of splitting & $:$ Easy \\
\hline Flesh stickiness & $:$ Slightly sticky \\
\hline seed length (cm) & $: 4.5-5$ \\
\hline seed width (cm) & $: 2.5-3$ \\
\hline Seed shape & $:$ Ellipsoid \\
\hline Seed coat color & $:$ Brown \\
\hline Seed coat color intensity & $:$ Dark \\
\hline
\end{tabular}

Source: Bioversity International (formerly International Plant Genetic Resources Institute (IPGRI), 2007. 